\title{
Ultrasonic-assisted plastic flow in a Zr-based metallic glass
}

\author{
Chenchen Yuan ${ }^{1 *}$, Zhuwei Lv ${ }^{1}$, Changmeng Pang ${ }^{1}, \mathrm{Xin} \mathrm{Li}^{2}$, Rui Liu ${ }^{1}$, Can Yang ${ }^{2}$, Jiang Ma ${ }^{2}$, \\ Haibo $\mathrm{Ke}^{3^{*}}$, Weihua Wang ${ }^{3,4}$ and Baolong Shen ${ }^{1^{*}}$
}

\begin{abstract}
Ultrasonic vibration can be used for the micromolding of metallic glasses (MGs) due to stress-softening and fast surface-diffusion effects. However, the structural rearrangement under ultrasonic vibration and its impact on the mechanical response of metallic glasses remain a puzzle. In this work, the plastic flow of the $\mathrm{Zr}_{35} \mathrm{Ti}_{30} \mathrm{Cu}_{8.25} \mathrm{Be}_{26.75}$ metallic glass with the applied ultrasonic-vibration energy of $140 \mathrm{~J}$ was investigated by nanoindentation. Both Kelvin and MaxwellVoigt models have been adopted to analyze the structural evolution during the creep deformation. The increase of the characteristic relaxation time and the peak intensity of relaxation spectra can be found in the sample after ultrasonic vibration. It effectively improves the activation energy of atomic diffusion during the glass transition $\left(E_{\mathrm{g}}\right)$ and the growth of the crystal nucleus $\left(E_{\mathrm{p}}\right)$. A more homogenous plastic deformation with a weak loading-rate sensitivity of stress exponent is observed in the ultrasonic-vibrated sample, which coincides with the low pile-up and penetration depth as shown in the cross profile of indents. The structural rearrangement under resonance actuation demonstrated in this work might help us better understand the defect-activation mechanism for the plastic flow of amorphous systems.
\end{abstract}

Keywords: plastic deformation, disordered structure, activation energy, metallic glass

\section{INTRODUCTION}

Structural tailoring is important for the mechanical performance of metallic glasses (MGs) [1]. The plastic flow of MGs is proposed to be closely related to structural rearrangement at the atomic scale during deformation. Zr-based MGs are typical MG systems that show superplastic deformation at room temperature [2-4]. It has been proved that $\mathrm{Zr}_{35} \mathrm{Ti}_{30} \mathrm{Cu}_{8.25} \mathrm{Be}_{26.75}$ can be microformed by using the ultrasonic-vibration technique [5]. Lateral extrusion experiments of the $\mathrm{Zr}_{55} \mathrm{Cu}_{30} \mathrm{Al}_{10} \mathrm{Ni}_{5} \mathrm{MG}$ with low-frequency vibration also reveal an enhanced micro-formability under vibratory loading [6]. Microhoneycomb structures with various pitches between adjacent cells are hot-embossed on the $\mathrm{Zr}_{35} \mathrm{Ti}_{30} \mathrm{Cu}_{8.25} \mathrm{Be}_{26.75}$ MG to improve its frictional behavior [7]. The ultrasonic stress-softening effect, stress superposition effect, and periodic separation originating from ultrasonic vibration can effectively improve the micro-formability via a reduction of the forming force and a decrease in friction at the interface [8-10]. The shear-deformation performance of MGs is also influenced by ultrasonic vibration [11]. High-frequency ultrasonic beating method to fabricate micro- to macro-scale structures $[12,13]$ can avoid the crystallization and oxidation of MGs, implying the potential application of this technique in micromachining MGs. The fast surface dynamics near the bonding interface under ultrasonic vibration enables cold joining of alloys/MGs of different types, which is beneficial for synthesizing multifunctional glassy composites with tunable sizes $[14,15]$. However, the structural evolution of MGs under ultrasonic vibration and the underlying physical origin for vibration-assisted plastic flow of MGs still remain unknown. Nanoindentation is a convenient technique that can be utilized to detect the mechanical response during the plastic deformation of structural materials, especially for glassy materials such as ceramics, oxide glasses, and MGs [16-18].

In this work, by using nanoindentation, the creep behavior of $\mathrm{Zr}_{35} \mathrm{Ti}_{30} \mathrm{Cu}_{8.25} \mathrm{Be}_{26.75}$ under ultrasonic vibration at ambient temperature was investigated. We found that

\footnotetext{
${ }^{1}$ School of Materials Science and Engineering, Jiangsu Key Laboratory for Advanced Metallic Materials, Southeast University, Nanjing 211189, China

${ }^{2}$ College of Mechatronics and Control Engineering, Shenzhen University, Shenzhen 518060, China

${ }^{3}$ Songshan Lake Materials Laboratory, Dongguan 523808, China

${ }^{4}$ Institute of Physics, Chinese Academy of Sciences, Beijing 100190, China

* Corresponding authors (emails: yuancc@seu.edu.cn (Yuan C); kehaibo@sslab.org.cn (Ke H); blshen@seu.edu.cn (Shen B))
} 
ultrasonic vibration with the applied energy of $140 \mathrm{~J}$ promoted the structural evolution of the Zr-based MGs into a more homogenous state, which effectively reduced the loading-rate sensitivity of stress exponent during the creep deformation as well as the activation energy for the nucleation of the crystalline $\left(E_{\mathrm{x}}\right)$. The shift of characteristic relaxation times to a long time region and the increase of the peak intensity of relaxation spectra can also be found in the ultrasonic-vibrated Zr-based MG, which coincides with the increase of activation energy for atomic diffusion during the glass transition $\left(E_{\mathrm{g}}\right)$ and for the growth of crystal nucleus $\left(E_{\mathrm{p}}\right)$. The nucleation of a large number of small "flow defects" along with the homogenous creep behavior under the frame of the Maxwell-Voigt model is proposed to play a key role in determining the excellent micro-formability of Zr-based MGs [8-12].

\section{EXPERIMENTAL SECTION}

The alloy with the nominal composition $\mathrm{Zr}_{35} \mathrm{Ti}_{30} \mathrm{Cu}_{8.25^{-}}$ $\mathrm{Be}_{26.75}$ was prepared by arc melting mixtures of pure $\mathrm{Zr}$, $\mathrm{Ti}, \mathrm{Cu}$, and $\mathrm{Be}(>99.99$ wt.\%) in a high-purity argon atmosphere (> 99.99 wt.\%). The cylindrical rods with a diameter of $2 \mathrm{~mm}$ were fabricated by a water-cooled copper crucible casting method. The samples cut from the as-cast rods with a height of $1.5 \mathrm{~mm}$ were ultrasonically vibrated by BRANSON 2000X ea/ae at the energy of $140 \mathrm{~J}$, the amplitude of $100 \%$, and the frequency of $20,000 \mathrm{~s}^{-1}$. The amorphous nature of the as-cast and ultrasonic-vibrated samples was confirmed by X-ray diffraction (XRD, Bruker D8 Discover diffractometer) with $\mathrm{Cu} \mathrm{Ka}$ radiation. The thermodynamic properties of two MGs were detected by NETZSCH 404 F3 differential scanning calorimeter (DSC). The creep measurements were conducted by using a NanoTest Vantage (Micro Materials Ltd) with a standard Berkovich diamond indenter. A standard fused silica sample was utilized for calibration (see details in Ref. [19]). The corresponding load and displacement resolutions were $3 \mathrm{nN}$ and $0.001 \mathrm{~nm}$, respectively. The surface morphology around the indents was traced by a Veeco Dimension ICON atomic force microscope (AFM). At least five indentation tests were carried out under each condition without considering the data that were biased obviously against

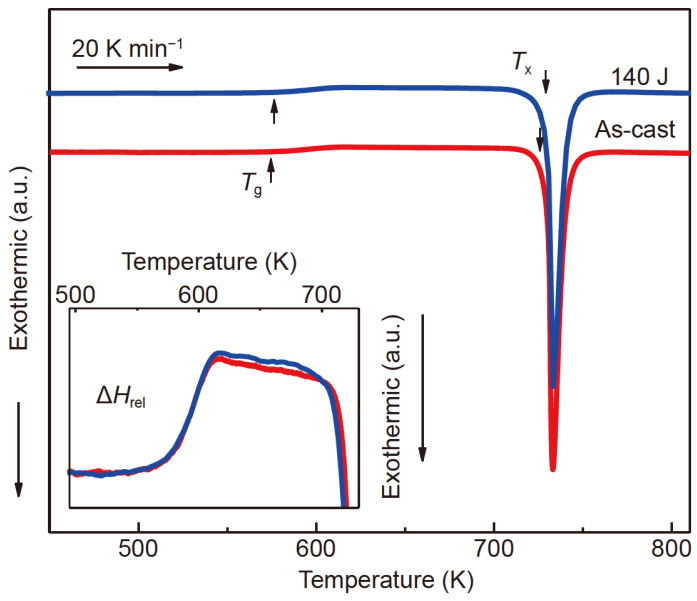

Figure 1 DSC curves of the ultrasonic-vibrated $\mathrm{Zr}_{35} \mathrm{Ti}_{30} \mathrm{Cu}_{8.25} \mathrm{Be}_{26.75} \mathrm{MG}$ with the applied energy of $140 \mathrm{~J}$ at a heating rate of $20 \mathrm{~K} \mathrm{~min}^{-1}$. The data for the as-cast sample were plotted for comparison. The inset shows the enthalpy recovery measurement.

the others.

\section{RESULTS AND DISCUSSION}

\section{Thermophysical properties}

Fig. 1 shows the DSC trace of the $\mathrm{Zr}_{35} \mathrm{Ti}_{30} \mathrm{Cu}_{8.25} \mathrm{Be}_{26.75} \mathrm{MG}$ after ultrasonic vibration with the applied energy of $140 \mathrm{~J}$ at a heating rate of $20 \mathrm{~K} \mathrm{~min}^{-1}$. The data for the as-cast sample is also plotted for comparison. A pronounced main exothermic peak after the weakly endothermic feature demonstrates a clear glass transition in both the as-cast and ultrasonic-vibrated samples. The glass transition temperature $T_{\mathrm{g}}$, crystallization temperature $T_{\mathrm{x}}$, and the supercooled region $\Delta T_{\mathrm{x}}=\left(T_{\mathrm{x}}-T_{\mathrm{g}}\right)$ are listed in Table 1. $T_{\mathrm{g}}, T_{\mathrm{x}}$, and $\Delta T_{\mathrm{x}}$ increase slightly after high-frequency vibration. The inset in Fig. 1 shows the enlarged view of the thermal trace near $T_{\mathrm{g}}$. A negligible change of the exothermic heat $\Delta H_{\text {rel }}$ [20] upon ultrasonic vibration is observed. It means the excess free volume $(\Delta v)$ derived by $\Delta v \propto \Delta H_{\text {rel }}=\int(\mathrm{d} Q / \mathrm{d} t) \mathrm{d} T$ [21] almost keeps constant without structural relaxation as indicated during the annealing process [22].

\section{Nanoindentation creep deformation}

Fig. 2a and b present the typical load-displacement $(P-h)$

Table 1 Thermal parameters of the as-cast and $140 \mathrm{~J}$ ultrasonic-vibrated $\mathrm{Zr}_{35} \mathrm{Ti}_{30} \mathrm{Cu}_{8.25} \mathrm{Be}_{26.75} \mathrm{MG}$ samples

\begin{tabular}{ccccccccccc}
\hline & $T_{\mathrm{g}}(\mathrm{K})$ & $T_{\mathrm{x}}(\mathrm{K})$ & $\Delta T(\mathrm{~K})$ & $\Delta H\left(\mathrm{~kJ} \mathrm{~mol}^{-1}\right)$ & $E_{\mathrm{g}}\left(\mathrm{kJ} \mathrm{mol}^{-1}\right)$ & $E_{\mathrm{x}}\left(\mathrm{kJ} \mathrm{mol}^{-1}\right)$ & $E_{\mathrm{p}}\left(\mathrm{kJ} \mathrm{mo}{ }^{-1}\right)$ & $k_{0 \mathrm{~g}}\left(\mathrm{~s}^{-1}\right)$ & $k_{0 \mathrm{x}}\left(\mathrm{s}^{-1}\right)$ & $k_{0 \mathrm{p}}\left(\mathrm{s}^{-1}\right)$ \\
\hline As-cast & 575 & 726 & 151 & 7.455 & 265 & 188 & 179 & $3.95 \times 10^{22}$ & $4.72 \times 10^{11}$ & $6.48 \times 10^{10}$ \\
$140 \mathrm{~J}$ & 577 & 729 & 152 & 7.552 & 285 & 174 & 194 & $2.57 \times 10^{24}$ & $4.41 \times 10^{10}$ & $9.29 \times 10^{11}$ \\
\hline
\end{tabular}



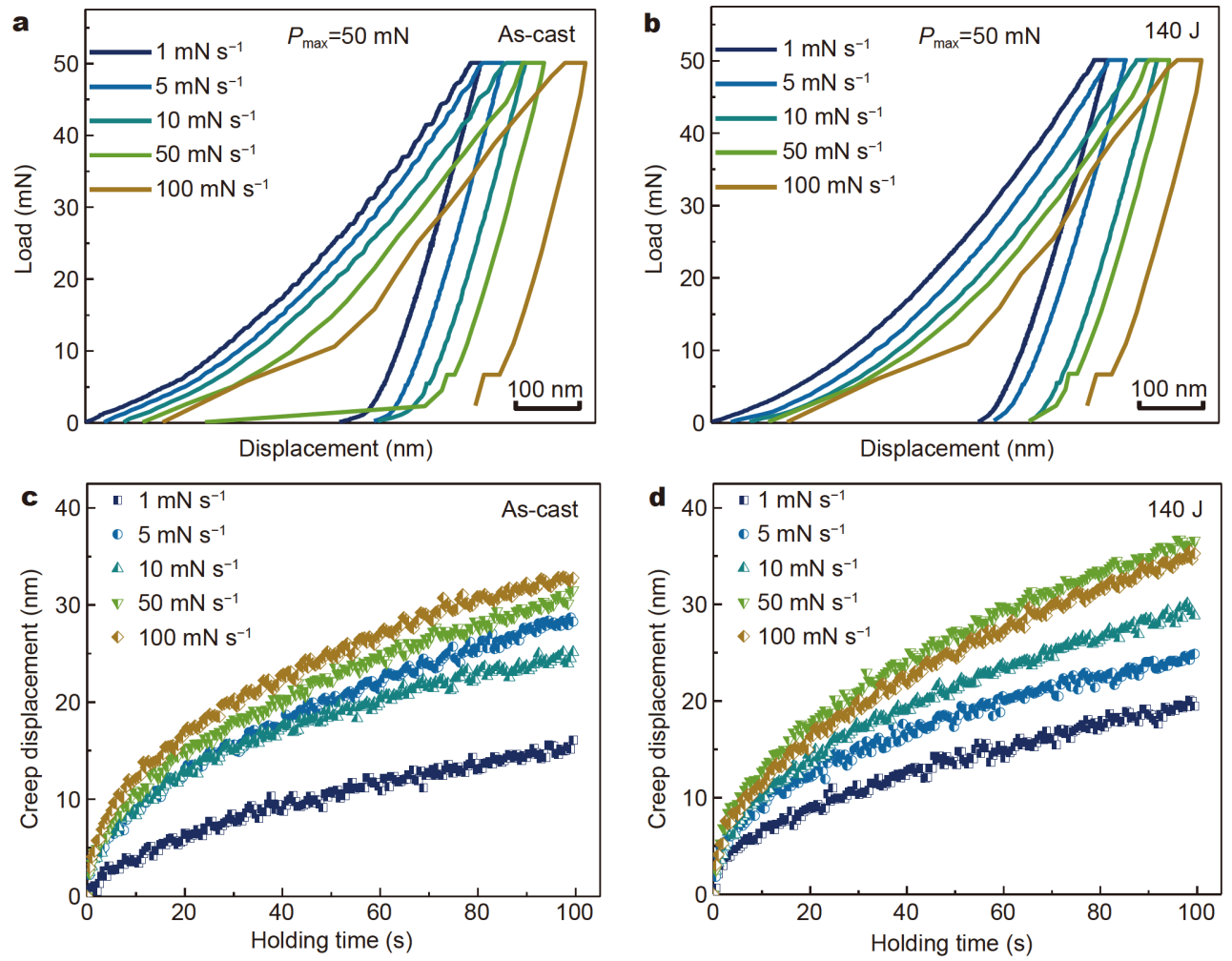

Figure 2 Creep behaviors of the $\mathrm{Zr}_{35} \mathrm{Ti}_{30} \mathrm{Cu}_{8.25} \mathrm{Be}_{26.75}$ MG samples. (a, b) Load-displacement $(P-h)$ curves under different loading rates of the as-cast (a), and $140 \mathrm{~J}$ ultrasonic-vibrated (b) samples. The curves in (a) and (b) offset from the origin for clear viewing. (c, d) The creep displacement of the as-cast (c) and $140 \mathrm{~J}$ ultrasonic-vibrated (d) samples during load holding period under different rates.

curves of the as-cast and ultrasonic-vibrated samples at a load limit of $50 \mathrm{mN}$, where $P$ is the loading force and $h$ the instantaneous indenter displacement. The samples were loaded at constant loading rates of $1,5,10,50$, and $100 \mathrm{mN} \mathrm{s}^{-1}$ to a load limit of $50 \mathrm{mN}$, then held for $100 \mathrm{~s}$ before unloaded at the same rate as the loading rate. It is interesting to notice that a serrated flow behavior is found in the as-cast MG during nanoindentation at a low loading rate. As shown in Fig. 2a, the pop-in step increases obviously with the applied load. This phenomenon implies the propagation of multiple shear bands at the initial loading process of the as-cast sample, especially at the loading rate of $1 \mathrm{mN} \mathrm{s}^{-1}$. With further increasing loading rates, the serration disappears gradually. It is not the case for the $140 \mathrm{~J}$ ultrasonic-vibrated sample. It displays more homogenous plastic flow during nanoindentation after the vibration treatment, even at a low loading rate of $1 \mathrm{mN} \mathrm{s}^{-1}$ (Fig. 2b). The creep displacement curves with the constant holding load of $50 \mathrm{mN}$ are displayed in Fig. $2 \mathrm{c}$ and d. With increasing loading rates from 1 to $100 \mathrm{mN} \mathrm{s}^{-1}$, the maximum creep displacement increases from 15 to more than $30 \mathrm{~nm}$, which is close to the reported value of 18 to $37 \mathrm{~nm}$ in the $\left(\mathrm{Co}_{0.7} \mathrm{Fe}_{0.3}\right)_{0.68^{-}}$ $\mathrm{B}_{0.219} \mathrm{Si}_{0.051} \mathrm{Nb}_{0.05}$ MG [19]. It demonstrates that the creep displacement of $\mathrm{Zr}$-based MGs is comparable to that of the MGs with a relatively high $T_{\mathrm{g}}$ at the same loading condition such as Co- [19], Fe- [23], and U-based [24] MGs. At the loading rate of $100 \mathrm{mN} \mathrm{s}^{-1}$, the maximum creep displacement of the ultrasonic-vibrated sample is $36 \mathrm{~nm}$, which is slightly higher than $33 \mathrm{~nm}$ of the as-cast sample.

\section{Local plastic deformation around indents}

AFM images are displayed in Fig. 3 to compare the local creep deformation around indents of the samples before and after vibration. No obvious shear band is observed in the pile-up region around the indent at the loading rate of $5 \mathrm{mN} \mathrm{s}^{-1}$, seen in Fig. 3a-d. It further verifies that a homogenous creep deformation occurs during the nanoindentation process at a high loading rate $[25,26]$. As shown in Fig. 3e and f, the pile-up around the indent can be evaluated by using topographic profiles. Compared with the $140 \mathrm{~J}$ ultrasonic-vibrated sample, the significant pile-up around indents of the as-cast sample indicates 
a

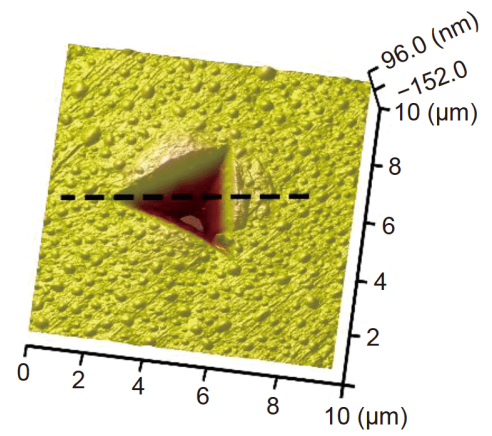

c
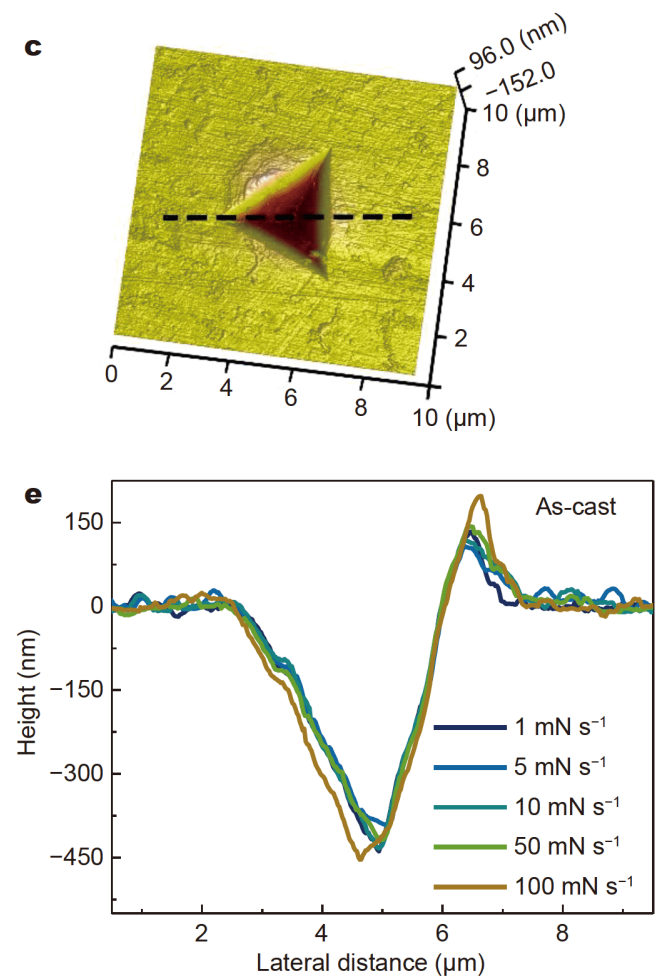

b

As-cast

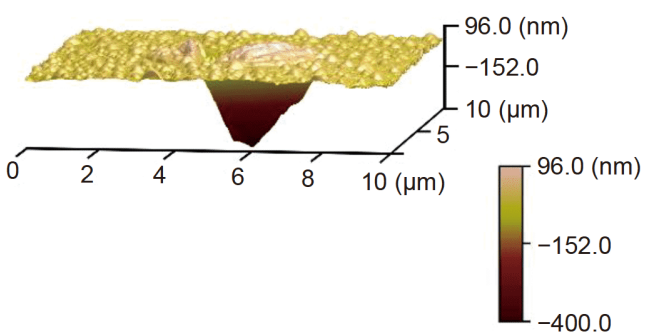

d
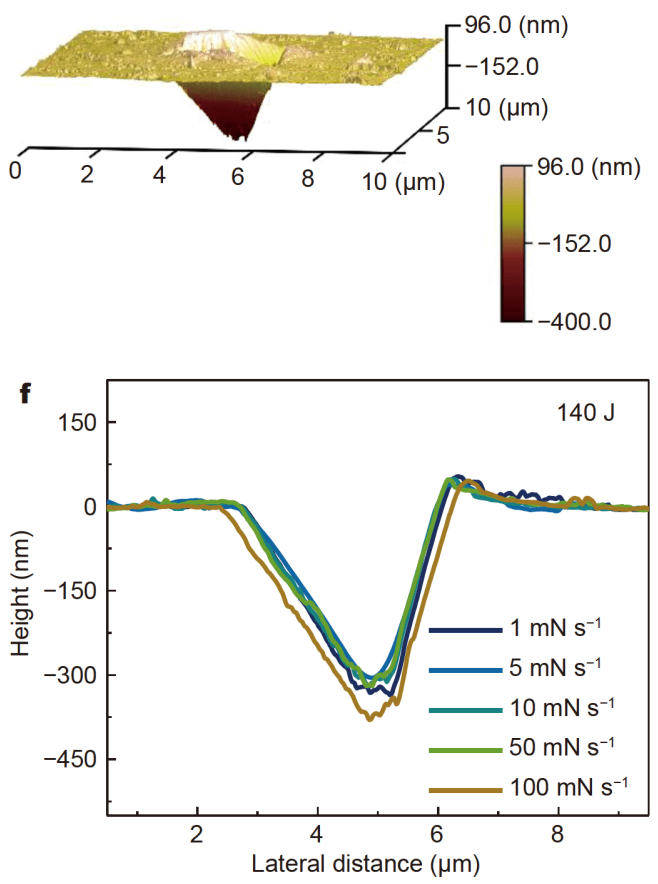

Figure $3 \mathrm{AFM}$ images of the as-cast (a, b) and $140 \mathrm{~J}$ ultrasonic-vibrated (c, d) $\mathrm{Zr}_{35} \mathrm{Ti}_{30} \mathrm{Cu}_{8.25} \mathrm{Be}_{26.75}$ MGs after nanoindentation at a loading rate of $5 \mathrm{mN} \mathrm{s}^{-1}$. The cross profile of the indents after nanoindentation for the as-cast (e) and $140 \mathrm{~J}$ ultrasonic-vibrated (f) samples.

that a pronounced localized deformation occurs during the creep process. The maximum height of the pile-up around indent of the as-cast MG is about $108 \mathrm{~nm}$ at the loading rate of $5 \mathrm{mN} \mathrm{s}^{-1}$, which is about three times higher than $38 \mathrm{~nm}$ of the ultrasonic-vibrated MG. With increasing loading rates, the maximum height of the pileup increases obviously, reaching the highest value of $198 \mathrm{~nm}$ at the loading rate of $100 \mathrm{mN} \mathrm{s}^{-1}$. The remarkable increases of pile-up from 133 to $198 \mathrm{~nm}$ with increasing loading rates from 50 to $100 \mathrm{mN} \mathrm{s}^{-1}$, exhibiting an extremely localized deformation of the as-cast sample at a low-velocity impact mode. Consistent with the observation in $\left[\left(\mathrm{Co}_{0.7} \mathrm{Fe}_{0.3}\right)_{0.68} \mathrm{~B}_{0.219} \mathrm{Si}_{0.051} \mathrm{Nb}_{0.05}\right]_{100-x} \mathrm{Cu}_{x}(x=0,0.5)$
[19], the localized pile-up that appears around the indent is not with respect to a large deformation ability as suggested in the work of Kim et al. [27]. In contrast, it manifests the extremely localized deformation and the poor formability of the as-cast sample. This phenomenon might relate to the quenched-in structural heterogeneity of the as-cast sample due to the high cooling rate during the water-cooled copper-crucible casting process $[2,28]$. The much lower pile-up of the $140 \mathrm{~J}$ sample at a relatively wide region around the indent demonstrates a more homogeneous deformation of the ultrasonic-vibrated $\mathrm{Zr}$ based MG. It is noteworthy that the maximum penetration depth observed from the topographic profile of the 
as-cast MG is about $390 \mathrm{~nm}$ at the loading rate of $5 \mathrm{mN} \mathrm{s}^{-1}$, which is only $305 \mathrm{~nm}$ for the $140 \mathrm{~J}$ ultrasonicvibrated sample. This result further verifies a more homogenous plastic flow of the ultrasonic-vibrated MG, rather than the localized creep deformation.

\section{Kelvin model analysis}

This steady mechanical performance of the ultrasonicvibrated MG under distinct nanoindentation conditions is in accord with the results of stress exponents. According to the empirical power-law relationship between the strain rate and the stress $\sigma[29,30]$, the stress exponent $n$ can be derived by

$\dot{\varepsilon}=A \sigma^{n}$,

where $A$ is a temperature-dependence constant. Here, the strain rate is $\dot{\varepsilon}=\dot{h} / h$ and the stress $\sigma=P / 24.5 h^{2}$. As seen in Fig. $4 \mathrm{a}$, the creep displacement $h$ of the as-cast sample as a function of time $t$ at a loading rate of $5 \mathrm{mN} \mathrm{s}^{-1}$ can be fitted well using Kelvin model [29]

$$
h(t)=h_{0}+a\left(t-t_{0}\right)^{b}+k t,
$$

where $t_{0}, h_{0}, a, b$, and $k$ are fitting constants. From the slope plotted in Fig. 4b, we can obtain the stress exponent: $n=\partial \ln \dot{\varepsilon} / \partial \ln \sigma$. It is found that $n$ decreases significantly with decreasing applied stress, approaching a constant value towards the end of the holding period. Fig. $4 \mathrm{c}$ shows $n$ at a steady-state power-law creep stage as a function of loading rates. Here, five measurements are included to estimate the average value of $n$ and the standard error. With increasing loading rates from 1 to $100 \mathrm{mN} \mathrm{s}^{-1}$, the calculated $n$ exhibits a wavelike drop from 23 to 11 and 16 to 11 for the as-cast and $140 \mathrm{~J}$ ultrasonic-vibrated MGs, respectively. In coincidence with the creep behavior of other MGs with $T_{\mathrm{g}}$ much higher than the ambient temperature, such as Fe-based MGs [19,31], $n$ of the as-cast sample decreases with in- creasing loading rate, displaying a high sensitivity with the applied loading rate. For instance, in the as-cast $\left.\left[\left(\mathrm{Fe}_{0.6} \mathrm{Co}_{0.4}\right)_{0.75} \mathrm{~B}_{0.2} \mathrm{Si}_{0.05}\right]_{0.96} \mathrm{Nb}_{0.04}\right\}_{96} \mathrm{Cr}_{4} \mathrm{MG}$, the value of $n$ decreases gradually from 28.1 to 4.9 with increasing loading rates from 1 to $50 \mathrm{mN} \mathrm{s}^{-1}$ [31]. However, after the high-frequency vibration, $n$ becomes much steadier, which fluctuates around a constant value of 12 at different loading rates.

In fact, the stress exponent $n$ of MGs is quite sensitive to the applied stress, which depends on both the indentation loading rates and peak loads applied in different MGs [32]. In the $\mathrm{Cu}_{50} \mathrm{Zr}_{50}$ MG, the value of $n$ almost obeys a linear relation with loading rates. It increases from 4 to 10 with increasing loading rates from 0.1 to $2.5 \mathrm{mN} \mathrm{s}^{-1}$ [33]. However, the loading-rate dependency of $n$ in Fe-based MGs [19,31], as well as our studied $\mathrm{Zr}$ based MG, differs from that in the $\mathrm{Cu}-\mathrm{Zr}$ MG. As reported in the work of Huang et al. [32], the $n$ of the $\mathrm{Fe}_{41} \mathrm{Co}_{7} \mathrm{Cr}_{15} \mathrm{Mo}_{14} \mathrm{C}_{15} \mathrm{~B}_{6} \mathrm{Y}_{2} \mathrm{MG}$ drops from 4.93 to 0.94 when increasing loading rates from 0.01 to $2.5 \mathrm{mN} \mathrm{s}^{-1}$, consistent with the observations in $\left[\left(\mathrm{Fe}_{0.6} \mathrm{Co}_{0.4}\right)_{0.75} \mathrm{~B}_{0.2^{-}}\right.$ $\left.\left.\mathrm{Si}_{0.05}\right]_{0.96} \mathrm{Nb}_{0.04}\right\}_{96} \mathrm{Cr}_{4}$ [31] and $\mathrm{Zr}_{35} \mathrm{Ti}_{30} \mathrm{Cu}_{8.25} \mathrm{Be}_{26.75}$ MGs. Besides, with increasing indentation sizes or contact depths due to the increase of the peak loads, the value of $n$ increases rapidly from 2.87 to 6.37 in this Fe-based MG.

\section{Hardness and elastic modulus}

The hardness $(H)$ and elastic modulus $(E)$ obtained from nanoindentation at the loading rates ranging from 1 to $100 \mathrm{mN} \mathrm{s}^{-1}$ are listed in Table 2. The $H$ and $E$ are barely influenced by the ultrasonic vibration. With increasing loading rates, the $H$ of the as-cast sample slightly decreases from 6.2 to $5.3 \mathrm{GPa}$, while the $E$ increases from 107 to $118 \mathrm{GPa}$. After vibration, the value of $H$ and $E$ almost unchanged. $H$ decreases from 6.6 to $5.7 \mathrm{GPa}$, and
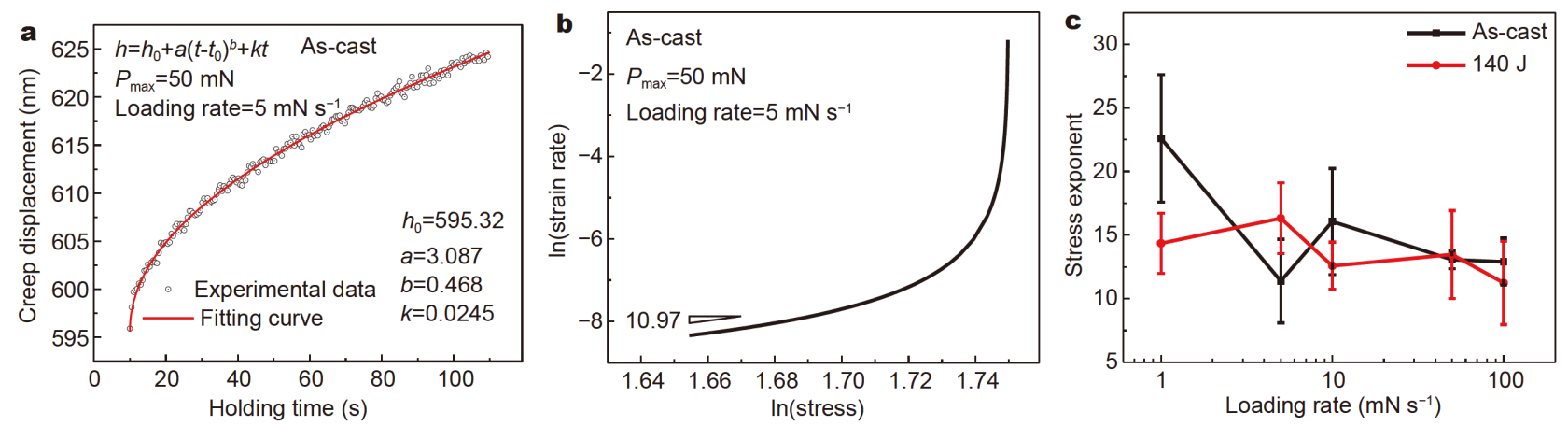

Figure 4 (a) The typical experimental and fitted creep curves of the as-cast $\mathrm{Zr}_{35} \mathrm{Ti}_{30} \mathrm{Cu}_{8.25} \mathrm{Be}_{26.75} \mathrm{MG}$ at a loading rate of $5 \mathrm{mN} \mathrm{s}{ }^{-1}$ by using the Kelvin model. (b) The $\ln$ (strain rate)- $\ln ($ stress) plot. (c) Steady-state stress exponent, $n$, of the as-cast and ultrasonic-oscillated MGs as a function of indentation loading rates. The solid lines are guides for the eyes. 


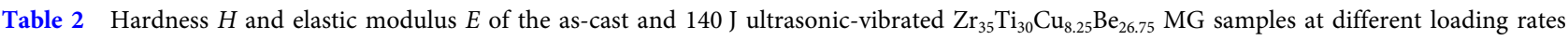

\begin{tabular}{|c|c|c|c|c|}
\hline \multirow{2}{*}{ Loading rate $\left(\mathrm{mN} \mathrm{s}^{-1}\right)$} & \multicolumn{2}{|c|}{$H(\mathrm{GPa})$} & \multicolumn{2}{|c|}{$E(\mathrm{GPa})$} \\
\hline & As-cast & $140 \mathrm{~J}$ & As-cast & $140 \mathrm{~J}$ \\
\hline 1 & $6.15 \pm 0.33$ & $6.56 \pm 0.35$ & $106.90 \pm 1.65$ & $107.24 \pm 3.25$ \\
\hline 5 & $6.20 \pm 0.21$ & $6.12 \pm 0.13$ & $106.00 \pm 1.63$ & $103.69 \pm 1.52$ \\
\hline 10 & $6.05 \pm 0.09$ & $6.22 \pm 0.24$ & $105.54 \pm 1.05$ & $104.58 \pm 2.46$ \\
\hline 50 & $5.86 \pm 0.07$ & $6.14 \pm 0.20$ & $109.55 \pm 1.63$ & $107.84 \pm 2.22$ \\
\hline 100 & $5.27 \pm 0.23$ & $5.69 \pm 0.27$ & $118.07 \pm 2.57$ & $115.22 \pm 4.27$ \\
\hline
\end{tabular}

$E$ increases from 107 to $115 \mathrm{GPa}$, when the loading rate increases from 1 to $100 \mathrm{mN} \mathrm{s}^{-1}$.

\section{Maxwell-Voigt model analysis}

If we consider both anelastic and viscoplastic deformation of MGs, the creep displacement in the nanoindentation process is more likely to be described by the MaxwellVoigt model that contains both Maxwell and Kelvin units mutually interaction in series. Herein, the displacement $h$ can be expressed as [34]

$h=h_{0}+\sum_{i=1}^{n} h_{i}\left(1-\mathrm{e}^{-t / \tau_{i}}\right)+t / \mu_{0}$,

where $h_{i}$ is the $i$-th indentation displacement, $\tau_{i}$ the characteristic relaxation time for the activation of the $i$-th anelastic Kelvin unit, $\mu_{0}$ a constant proportional to the viscosity coefficient of the Maxwell dashpot, and $h_{0}$ the indentation displacement at the beginning of the holding stage. The two-phase model as proposed in MGs can be characterized by two anelastic relaxation processes during the creeping process [35]. Therefore, two Kelvin units with a Maxwell unit [24] were chosen to analyze the creep displacement of the studied MGs, i.e., $n=2$. As shown in Fig. $5 \mathrm{a}$ and $\mathrm{b}$, the typical creep data of the as-cast and $140 \mathrm{~J}$ ultrasonic-vibrated samples at different loading rates can be fitted well by using the Maxwell-Voigt model based on the two-phase hypothesis

$h=h_{1}\left(1-\mathrm{e}^{-t / \tau}\right)+h_{2}\left(1-\mathrm{e}^{-t / \tau} 2\right)+t / \mu_{0}$,

where $h_{1}$ and $\tau_{1}$ represent the displacement and relaxation time of the first Kelvin unit, $h_{2}$ and $\tau_{2}$ represent that of the second Kelvin unit, and $\mu_{0}$ is a constant coefficient related to the Maxwell unit. The initial displacement $h_{0}$ in Equation (3) is set as 0. It is seen that structural heterogeneity at the nanoscale as found in many MGs $[28,36-$ 38 ] can be precisely described by two characteristic relaxation time $\tau_{1}$ and $\tau_{2}$ by using the two-phase model (Fig. 5c), namely, the glassy matrix that possesses more defects with long relaxation time (i.e., large size) will show a relatively low hardness or elastic modulus relating to soft regions, while that with more small defects (short relaxation time) relates to hard regions. The correlation coefficient $R^{2}$ is more than 0.99 at the loading rate of $5 \mathrm{mN} \mathrm{s}^{-1}$. The fitting parameters for the typical creep curves at different loading rates are listed in Table 3 . It is noticed that $\mu_{0}^{-1}$ that represents the viscoplastic deformation progressively increases with increasing loading rates, demonstrating an evident drop of viscosity upon the ascending loading rate in both the as-cast and ultrasonic-vibrated samples. Compared with the as-cast sample, $\mu_{0}{ }^{-1}$ of the $140 \mathrm{~J}$ ultrasonic-vibrated sample is slightly larger, exhibiting a more pronounced viscous flow behavior. The significant increase of the displacement as indicated by $h_{1}$ and $h_{2}$ with increasing loading rates can be observed in both the as-cast and ultrasonic-vibrated samples, accompanying the shift of characteristic relaxation times of two Kelvin units, $\tau_{1}$ and $\tau_{2}$ towards a longer time region. This phenomenon demonstrates that more defects with a longer characteristic relaxation time are activated under the quasi-static loading mode. At the loading rate higher than $50 \mathrm{mN} \mathrm{s}^{-1}$, the $h$ and $\tau$ of two Kelvin units start to drop, especially for the $140 \mathrm{~J}$ ultrasonic-vibrated sample. This scenario suggests a saturation of activated defects under the low-velocity impact mode.

As proposed in the work of Castellero et al. [35], the relaxation time spectrum based on the Maxwell-Voigt model can accurately describe the two anelastic creep processes of MGs [39]

$L(\tau)=\left.\left[\sum_{i=1}^{n}\left(1+\frac{t}{\tau_{i}}\right) \frac{h_{i}}{\tau_{i}} \mathrm{e}^{-t / \tau_{i}}\right] \frac{A_{0}}{P_{0} h_{i n}} t\right|_{t=2 \tau}$,

where $L$ is the spectrum intensity, $A_{0} / P_{0}$ the inverse of the hardness $H$, and $h_{i n}$ the maximum indentation depth. Here, $n=2$. Fig. $5 d-f$ give the relaxation spectra of the ascast and ultrasonic vibrated MGs at different loading rates. The observed two separate relaxation peaks in each relaxation spectra are related to two relaxation processes demonstrated by two characteristic relaxation times $\tau_{1}$ and $\tau_{2}$ under the Maxwell-Voigt model. With increasing 

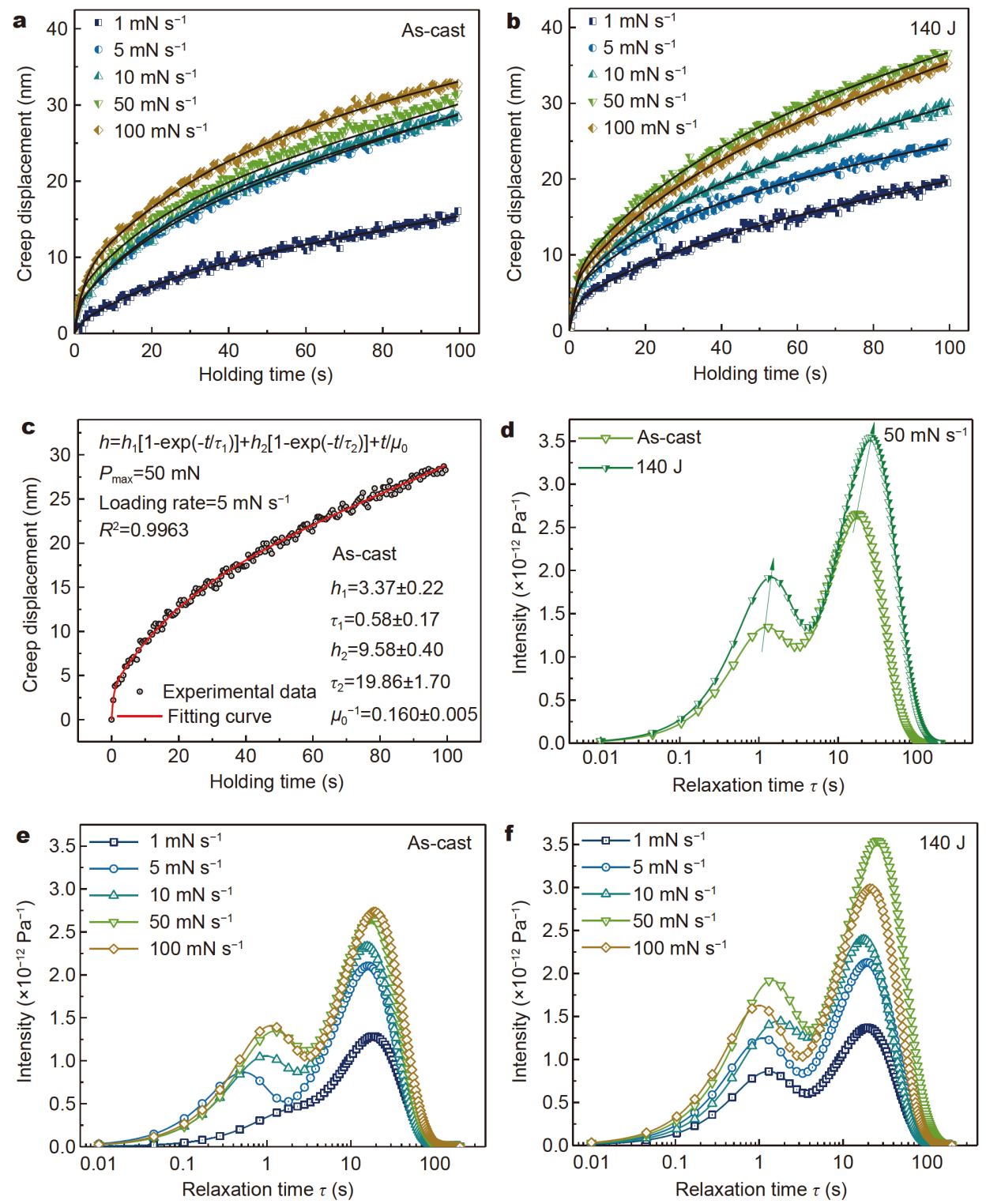

Figure 5 The creep displacement and fitting curves of the as-cast (a) and $140 \mathrm{~J}$ ultrasonic-vibrated (b) $\mathrm{Zr}_{35} \mathrm{Ti}_{30} \mathrm{Cu}_{8.25} \mathrm{Be}_{26.75} \mathrm{MGs}$ by using the MaxwellVoigt model during the load holding period at different loading rates. (c) The typical experimental and fitted creep curves of the as-cast sample at a loading rate of $5 \mathrm{mN} \mathrm{s}^{-1}$ by using the Maxwell-Voigt model. (d) The typical relaxation time spectra of the samples before and after vibration at a loading rate of $50 \mathrm{mN} \mathrm{s}^{-1}$. Relaxation time spectra of the as-cast (e) and $140 \mathrm{~J}(\mathrm{f})$ ultrasonic-vibrated samples based on the anelastic part of creep curves at different loading rates.

loading rates from 1 to $100 \mathrm{mN} \mathrm{s}^{-1}$, both the peak intensity and relaxation time of the first and second peaks alter notably. This phenomenon reveals that more defects are activated along with the generation of free volumes $[24,35]$. It agrees well with our previous observations in $\left[\left(\mathrm{Co}_{0.7} \mathrm{Fe}_{0.3}\right)_{0.68} \mathrm{~B}_{0.219} \mathrm{Si}_{0.051} \mathrm{Nb}_{0.05}\right]_{100-x} \mathrm{Cu}_{x}(x=0,0.5)$ that the excess free volume generated during the creep deformation can be simulated at a high loading rate [19]. This process might benefit the propagation of "flow de- fects" such as shear transition zones [40]. The superposition of the atomic clusters inside those defects during deformation together with the generation of plenty of free volumes is in favor of a pronounced creep deformation via the homogeneous plastic flow under the indenter. Based on the core-shell theory [41], the defect with more free volume is able to dissipate the stress concentrates in the elastic matrix by consuming a long relaxation time. Herein, the Kelvin unit has a close correlation with these 
Table 3 The fitting parameters of creep curves of the as-cast and $140 \mathrm{~J}$ ultrasonic-vibrated $\mathrm{Zr}_{35} \mathrm{Ti}_{30} \mathrm{Cu}_{8.25} \mathrm{Be}_{26.75} \mathrm{MG}$ samples based on the MaxwellVoigt model

\begin{tabular}{ccccccc}
\hline Sample & Loading rate $\left(\mathrm{mN} \mathrm{s}^{-1}\right)$ & $h_{1}(\mathrm{~nm})$ & $\tau_{1}(\mathrm{~s})$ & $h_{2}(\mathrm{~nm})$ & $\tau_{2}(\mathrm{~s})$ & $\mu_{0}^{-1}(\mathrm{~nm} \mathrm{~s})$ \\
\hline & 1 & $1.01 \pm 0.34$ & $1.61 \pm 1.19$ & $5.91 \pm 0.53$ & $22.91 \pm 4.55$ & $0.086 \pm 0.007$ \\
& 5 & $3.37 \pm 0.22$ & $0.58 \pm 0.17$ & $9.58 \pm 0.39$ & $19.86 \pm 1.70$ & $0.160 \pm 0.005$ \\
As-cast & 10 & $3.65 \pm 0.27$ & $0.96 \pm 0.22$ & $10.54 \pm 0.36$ & $19.21 \pm 1.55$ & $0.108 \pm 0.005$ \\
& 50 & $4.55 \pm 0.29$ & $1.23 \pm 0.21$ & $11.83 \pm 0.46$ & $21.63 \pm 1.85$ & $0.148 \pm 0.006$ \\
& 100 & $4.56 \pm 0.24$ & $1.16 \pm 0.17$ & $11.07 \pm 0.52$ & $23.68 \pm 2.10$ & $0.131 \pm 0.006$ \\
\hline & 1 & $3.23 \pm 0.31$ & $1.36 \pm 0.34$ & $6.29 \pm 0.67$ & $24.37 \pm 4.92$ & $0.103 \pm 0.008$ \\
$140 \mathrm{~J}$ & 5 & $4.79 \pm 0.30$ & $1.17 \pm 0.21$ & $9.86 \pm 0.69$ & $24.17 \pm 3.15$ & $0.102 \pm 0.009$ \\
& 10 & $4.71 \pm 0.33$ & $1.61 \pm 0.24$ & $10.63 \pm 0.43$ & $21.71 \pm 2.11$ & $0.144 \pm 0.006$ \\
& 50 & $7.03 \pm 0.27$ & $1.50 \pm 0.15$ & $15.83 \pm 1.28$ & $31.73 \pm 3.51$ & $0.146 \pm 0.013$ \\
\hline
\end{tabular}

"flow defects" as demonstrated in the relaxation spectra [42].

Compared with the as-cast sample, the relaxation time spectra of the $140 \mathrm{~J}$ ultrasonic-vibrated sample are more sensitive to the loading rate, especially at a loading rate higher than $10 \mathrm{mN} \mathrm{s}^{-1}$. For intense, a remarkable increase of the intensity of the first and secondary relaxation peaks at the loading rates of $50 \mathrm{mN} \mathrm{s}^{-1}$ is observed in the ultrasonic-vibrated sample (Fig. 5d). It implies that more defects at both short and long relaxation times are activated at higher loading rates after treatment by vibration. Meanwhile, the characteristic relaxation time shifts to a longer time region at this loading rate. It means defects of the ultrasonic-vibrated sample with large sizes are more likely to be stimulated at a higher loading rate.

Fig. 5e and $\mathrm{f}$ display the typical relaxation time spectra of the as-cast and ultrasonic-vibration samples as a function of the loading rate. The significant increase of the characteristic relaxation time $\tau_{2}$ and its peak intensity in relaxation spectra is found in the $140 \mathrm{~J}$ ultrasonicvibrated sample. It suggests that compared with the ascast sample, more defects with large sizes and long relaxation times are propagated in the ultrasonic-vibrated sample at a higher loading rate. Meanwhile, both the first and secondary peaks of the as-cast and ultrasonic-vibrated samples in the relaxation spectra shift to a longer time region with increasing loading rates, especially for the sample after vibration. It illustrates that the size of the activated defects becomes larger when the loading mode changes from a quasi-static to dynamic mode.

Two characteristic relaxation peaks have also been found in the relaxation spectra of many other MGs such as U- [24], Ce-, La- [43], Mg- [35], Ti-based MGs [44] as well as Ti-Zr-Hf-Be-Cu-(Ni) high-entropy MGs [45]. As demonstrated in Ti-Zr-Be MGs, both the first and secondary peaks show an increase in intensity and a shift towards longer relaxation times for the alloys with less creep resistance [44], which is in agreement with our present studies as well as the work of U-base MGs [24]. Moreover, the separate relaxation peaks that represent defects with different sizes seem to rely on the structural relaxation as well in addition to the loading rate [24]. For example, the relaxation spectra of $\mathrm{Mg}_{65} \mathrm{Cu}_{25} \mathrm{Y}_{10}$ show a progressive separation between two relaxation peaks during the annealing process [35].

\section{The activation energy for the glass transition as well as the} nucleation and growth of crystals

According to the classical Kissinger method, the activation energy $\left(E_{\mathrm{c}}\right)$ for the glass transition or crystallization of MGs at a constant heating rate can be derived in virtue of the thermodynamic parameters [46]

$\ln \left(\frac{T^{2}}{\theta}\right)=\frac{E_{\mathrm{c}}}{R T}+\ln \left(\frac{E_{\mathrm{c}}}{k_{0} R}\right)$,

where $T$ is the characteristic temperature such as $T_{\mathrm{g}}, T_{\mathrm{x}}$, and peak temperature $\left(T_{\mathrm{p}}\right), \theta$ the heating rate, $R$ the gas constant, and $k_{0}$ the frequency factor. Fig. $6 \mathrm{a}$ and $\mathrm{b}$ show typical DSC traces of the as-cast and $140 \mathrm{~J}$ ultrasonicvibrated MGs at different heating rates. It can be seen that the thermodynamic parameters like $T_{\mathrm{g}}, T_{\mathrm{x}}$, and $T_{\mathrm{p}}$ generally shift to the high-temperature regime with increasing heating rates from 5 to $40 \mathrm{~K} \mathrm{~min}^{-1}$. Kissinger plots of the two MGs are displayed in Fig. $6 \mathrm{c}$ and d. An approximate linear relation between $\ln \left(T^{2} / \theta\right)$ and $1000 / T$ is obtained. The activation energies, $E_{\mathrm{g}}, E_{\mathrm{x}}$, and $E_{\mathrm{p}}$ can be calculated according to the slope $E_{\mathrm{c}} / R$ in Equation (6). The values of $E_{\mathrm{g}}$ are 265 and $285 \mathrm{~kJ} \mathrm{~mol}^{-1}$ for the as-cast 

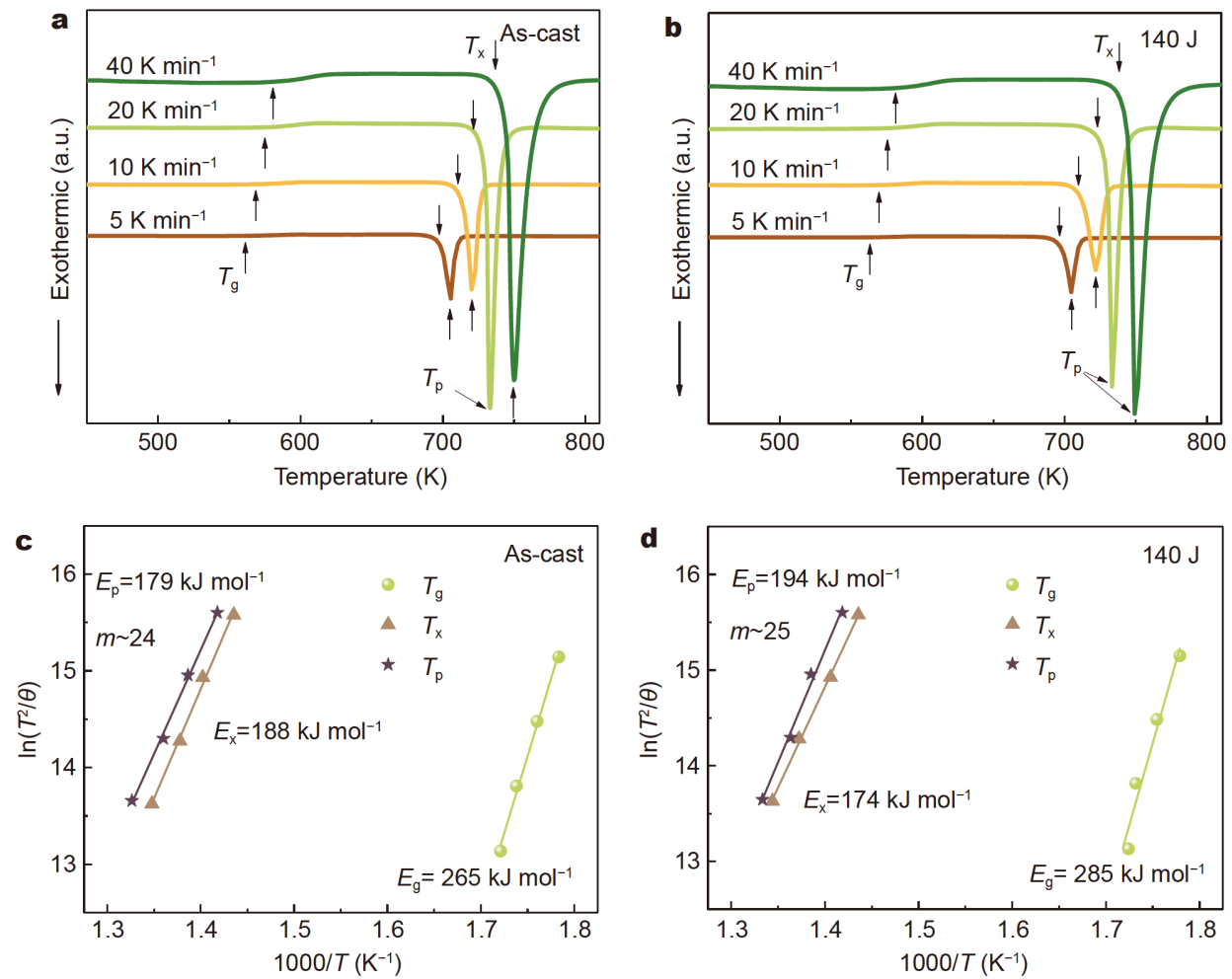

Figure 6 Thermodynamic and kinetic characteristic parameters of the $\mathrm{Zr}_{35} \mathrm{Ti}_{30} \mathrm{Cu}_{8.25} \mathrm{Be}_{26.75} \mathrm{MG}$ samples. DSC traces of the as-cast (a) and $140 \mathrm{~J}$ ultrasonic-vibrated (b) MGs at heating rates ranging from 5 to $40 \mathrm{~K} \mathrm{~min}^{-1}$. Kissinger plots of the as-cast (c) and $140 \mathrm{~J}$ ultrasonic-vibrated (d) MG samples to calculate the activation energies relative to $T_{\mathrm{g}}, T_{\mathrm{x}}$, and $T_{\mathrm{p}}$, respectively, and the fragility parameter $m$.

and ultrasonic-vibrated samples, respectively, which are between those of U-Co-Al alloy $\left(338 \mathrm{~kJ} \mathrm{~mol}^{-1}\right)$ [47] and $\mathrm{Pd}_{40} \mathrm{Ni}_{10} \mathrm{Cu}_{30} \mathrm{P}_{20}\left(228 \mathrm{~kJ} \mathrm{~mol}^{-1}\right)$ [48]. Compared with the as-cast sample, the ultrasonic-vibrated sample displays a $\sim 10 \%$ higher value of $E_{\mathrm{g}}$. It demonstrates that the energy barrier for atomic diffusion in the supercooled liquid region is elevated due to the vibration-assisted structural rearrangement of the $\mathrm{Zr}_{35} \mathrm{Ti}_{30} \mathrm{Cu}_{8.25} \mathrm{Be}_{26.75}$ MG. The larger diffusion activity energy impedes the extremely fast atomic motion inside these defects. This procedure prevents the local pile-up as observed around the indenter of the as-cast sample in AFM images. It can interpret the more homogeneous deformation observed in the ultrasonic-vibrated sample. However, the activation energy for nucleation, $E_{\mathrm{x}}$, is reduced from 188 to $174 \mathrm{~kJ} \mathrm{~mol}^{-1}$ after ultrasonic vibration, which implies that the incubation time for nucleation is shortened due to the appearance of multiple nucleation sites after the activation of massive characteristic defects. A large number of nucleation sites in the ultrasonic-vibrated sample can be indicated as "flow defects" in the relaxation time spectra, which promotes the propagation of shear transition zones [40], thereby, in favor of the plastic flow of MGs. Such struc- tural rearrangement coincides with local structural rejuvenation induced by the ultrasonic vibration as reported in the work of Wang et al. [49], which might be the underlying reason for the large creep deformation of the ultrasonic-vibrated sample as demonstrated in Fig. 5b.

On the other hand, the activation energy for the growth of crystal nuclei, $E_{\mathrm{p}}$ is elevated by about $8 \%$. It implies that the atomic motion during the crystal growth is impeded as well, which may hinder the crystallization behavior of the ultrasonic-vibrated sample. Thus, the highfrequency vibration method can be used to promote the glass-forming ability of MGs through tuning the nucleation and growth rates, which is beneficial to the industrial application of those high-strength glassy materials.

In Equation (6), $k_{0}$ is normally used to estimate the probability of an atom involved in glass transition or crystallization, which can also be calculated by the intercept $\ln \left(E_{c} / k_{0} R\right)$. As listed in Table 1 , the value of $k_{0}$ is $3.95 \times 10^{22} \mathrm{~s}^{-1}$ at $T_{\mathrm{g}}, 4.72 \times 10^{11} \mathrm{~s}^{-1}$ at $T_{\mathrm{x}}$, and $6.48 \times$ $10^{10} \mathrm{~s}^{-1}$ at $T_{\mathrm{p}}$ for the as-cast sample, and $2.57 \times 10^{24} \mathrm{~s}^{-1}$ at $T_{\mathrm{g}}, 4.41 \times 10^{10} \mathrm{~s}^{-1}$ at $T_{\mathrm{x}}$, and $9.29 \times 10^{11} \mathrm{~s}^{-1}$ at $T_{\mathrm{p}}$ for the ultrasonic-vibrated sample. $k_{0}$ at $T_{\mathrm{g}}$ of the ultrasonicvibrated sample is two orders of magnitude larger than 
that of the as-cast sample, while $k_{0}$ at $T_{\mathrm{p}}$ also rises about ten times after vibration. It suggests that more atoms participate in the glass transition as well as the growth of the crystalline phase. This implies that the number of the rearranged atoms during plastic deformation should increase accordingly, which could be the main reason that causes a more homogenous plastic flow of the ultrasonicvibrated sample during the creep process. Meanwhile, the decrease of the number of atoms required for the nucleation as indicated by the reduction of $k_{0}$ at $T_{\mathrm{x}}$ is consistent with more activated defects observed in the relaxation spectra and low energy barrier of nucleation of the ultrasonic-vibrated sample.

To investigate the dynamic behavior of the studied $\mathrm{Zr}$ based MGs under vibration, the fragility parameter $m$ is derived by using the equation according to the activation energy of atomic diffusion in the undercooled liquid region, $E_{\mathrm{g}}[50]$

$m=\left.\frac{\mathrm{d} \log \eta(T)}{\mathrm{d}\left(T_{\mathrm{g}} / T\right)}\right|_{T=T_{\mathrm{g}}}=\frac{E_{\mathrm{g}}}{\ln 10 R T_{\mathrm{g}}}$.

$\eta(T)$ is the viscosity that can be expressed as $\eta(T)=$ $\eta_{0} \exp \left(E / k_{\mathrm{B}} / T\right)$, where $\eta_{0}$ is the viscosity at the high-temperature limit, $E$ the activation energy for viscous flow, and $k_{\mathrm{B}}$ the Boltzmann constant. As seen in Fig. $6 \mathrm{c}$ and d, $m$ are 24 and $25 \mathrm{~kJ} \mathrm{~mol}^{-1}$ for the as-cast and ultrasonicvibrated samples, respectively. These values are slightly smaller than those of Ce-based (m 32-34) [51] and Ubased ( $m \sim 28$ ) [47] MGs. Generally, the glass-forming melts can be classified into two types, i.e., strong and fragile, according to the value of $m$, which is small for strong liquids and large for fragile liquids [52]. Thus, similar to U-based systems, the investigated Zr-based MG with $m \sim 24-25$ can be defined as a relatively strong glassforming liquid system. More importantly, the high-frequency vibration at room temperature has a weak impact on the viscous flow of the $\mathrm{Zr}_{35} \mathrm{Ti}_{30} \mathrm{Cu}_{8.25} \mathrm{Be}_{26.75} \mathrm{MG}$ when approaching $T_{\mathrm{g}}$ with $T_{\mathrm{g}} \sim 575-577 \mathrm{~K}$ that is $\sim 300 \mathrm{~K}$ above the ambient temperature.

\section{CONCLUSIONS}

In this work, the plastic flow accompanied by structural rearrangement at the atomic scale of the $\mathrm{Zr}_{35} \mathrm{Ti}_{30} \mathrm{Cu}_{8.25^{-}}$ $\mathrm{Be}_{26.75} \mathrm{MG}$ treated by ultrasonic-vibration with the energy of $140 \mathrm{~J}$ was thoroughly investigated. We found that for the Zr-based MG with $T_{\mathrm{g}}$ about $300 \mathrm{~K}$ higher than room temperature, the high-frequency vibration has a weak impact on its mechanical performances such as hardness, elastic modulus, and dynamic parameters like the fragility parameter $m$. However, DSC analysis shows that the activation energy for atomic diffusion during the glass transition, $E_{\mathrm{g}}$, increases about $10 \%$, together with the improved energy barrier for the crystal growth, $E_{\mathrm{p}}$, from 179 to $194 \mathrm{~kJ} \mathrm{~mol}^{-1}$. While the nucleation activation energy, $E_{\mathrm{x}}$, is reduced by $\sim 10 \%$, which might prevent the crystallization during the cooling process and is in favor of improving the glass-forming ability of MGs. Meanwhile, a more homogenous deformation can be observed in the ultrasonic-vibrated sample as demonstrated by a low and wide pile-up around the indent and a steady stress exponent $n$ at different loading rates. It may be the main reason for the large plastic flow during vibrationassisted micro-molding of Zr-based MGs.

\section{Received 29 April 2020; accepted 26 May 2020;}

published online 21 August 2020

1 Ma E, Zhu T. Towards strength-ductility synergy through the design of heterogeneous nanostructures in metals. Mater Today, 2017, 20: 323-331

2 Liu YH, Wang G, Wang RJ, et al. Super plastic bulk metallic glasses at room temperature. Science, 2007, 315: 1385-1388

3 Yuan CC, Xia XX, Jiang KH, et al. Effect of Sn additions on the damage tolerance of a $\mathrm{ZrCuNiAl}$ bulk metallic glass. Metal Mat Trans A, 2013, 44: 819-826

4 Zhu F, Song S, Reddy KM, et al. Spatial heterogeneity as the structure feature for structure-property relationship of metallic glasses. Nat Commun, 2018, 9: 3965

5 Han G, Peng Z, Xu L, et al. Ultrasonic vibration facilitates the micro-formability of a Zr-based metallic glass. Materials, 2018, 11: 2568

6 Li J, Zheng Z, Wu X, et al. A study on micro-forming ability of Zr55 bulk metallic glass under low frequency vibrating field. J Plasticity Eng, 2015, 22: 118-124

7 Li N, Xu E, Liu Z, et al. Tuning apparent friction coefficient by controlled patterning bulk metallic glasses surfaces. Sci Rep, 2016, 6: 39388

8 Huang YM, Wu YS, Huang JY. The influence of ultrasonic vibration-assisted micro-deep drawing process. Int J Adv Manuf Technol, 2014, 71: 1455-1461

9 Bai Y, Yang M. Investigation on mechanism of metal foil surface finishing with vibration-assisted micro-forging. J Mater Processing Tech, 2013, 213: 330-336

10 Han G, Li K, Peng Z, et al. A new porous block sonotrode for ultrasonic assisted micro plastic forming. Int J Adv Manuf Technol, 2017, 89: 2193-2202

11 Michalski M, Lechner M, Gruber M, et al. Influence of ultrasonic vibration on the shear formability of metallic materials. CIRP Ann, 2018, 67: 277-280

12 Liang X, Ma J, Wu XY, et al. Micro injection of metallic glasses parts under ultrasonic vibration. J Mater Sci Tech, 2017, 33: 703707

13 Luo F, Sun F, Li K, et al. Ultrasonic assisted micro-shear punching of amorphous alloy. Mater Res Lett, 2018, 6: 545-551

14 Ma J, Yang C, Liu X, et al. Fast surface dynamics enabled cold joining of metallic glasses. Sci Adv, 2019, 5: eaax7256 
$15 \mathrm{Xu} \mathrm{Z}$, Li Z, Zhong S, et al. Wetting mechanism of Sn to $\mathrm{Zr}_{507^{-}}$ $\mathrm{Cu}_{28} \mathrm{Ni}_{9} \mathrm{Al}_{12.3}$ bulk metallic glass assisted by ultrasonic treatment. Ultrasons SonoChem, 2018, 48: 207-217

16 Fischer-Cripps AC. Nanoindentation. New York: Springer-Verlag, 2002

17 He LH, Swain MV. Nanoindentation creep behavior of human enamel. J Biomed Mater Res, 2009, 91A: 352-359

18 Schuh CA, Nieh TG. A nanoindentation study of serrated flow in bulk metallic glasses. Acta Mater, 2003, 51: 87-99

19 Yuan CC, Lv ZW, Pang CM, et al. Pronounced nanoindentation creep deformation in $\mathrm{Cu}$-doped CoFe-based metallic glasses. J Alloys Compd, 2019, 806: 246-253

20 van den Beukel A, Sietsma J. The glass transition as a free volume related kinetic phenomenon. Acta Metall Mater, 1990, 38: 383-389

21 Slipenyuk A, Eckert J. Correlation between enthalpy change and free volume reduction during structural relaxation of $\mathrm{Zr}_{55} \mathrm{Cu}_{30^{-}}$ $\mathrm{Al}_{10} \mathrm{Ni}_{5}$ metallic glass. Scripta Mater, 2004, 50: 39-44

22 Yuan CC, Ma J, Xi XK. Understanding the correlation of plastic zone size with characteristic dimple pattern length scale on the fracture surface of a bulk metallic glass. Mater Sci Eng-A, 2012, 532: 430-434

23 Liao GK, Long ZL, Zhao MSZ, et al. Nanoindentation study of the creep behavior in a Fe-based bulk metallic glass. Mater Res Express, 2017, 4: 115202

24 Ke HB, Zhang P, Sun BA, et al. Dissimilar nanoscaled structural heterogeneity in U-based metallic glasses revealed by nanoindentation. J Alloys Compd, 2019, 788: 391-396

25 Li WH, Wei BC, Zhang TH, et al. Study of serrated flow and plastic deformation in metallic glasses through instrumented indentation. Intermetallics, 2007, 15: 706-710

26 Liu L, Chan KC. Plastic deformation of Zr-based bulk metallic glasses under nanoindentation. Mater Lett, 2005, 59: 3090-3094

27 Kim JT, Hong SH, Lee CH, et al. Plastic deformation behavior of Fe-Co-B-Si-Nb-Cr bulk metallic glasses under nanoindentation. J Alloys Compd, 2014, 587: 415-419

28 Yuan CC, Lv ZW, Pang CM, et al. Atomic-scale heterogeneity in large-plasticity $\mathrm{Cu}$-doped metallic glasses. J Alloys Compd, 2019, 798: 517-522

29 Li WB, Henshall JL, Hooper RM, et al. The mechanisms of indentation creep. Acta Metall Mater, 1991, 39: 3099-3110

30 Storåkers B, Larsson PL. On Brinell and Boussinesq indentation of creeping solids. J Mech Phys Solids, 1994, 42: 307-332

31 Xu F, Long Z, Deng X, et al. Loading rate sensitivity of nanoindentation creep behavior in a Fe-based bulk metallic glass. Trans Nonferrous Met Soc China, 2013, 23: 1646-1651

32 Huang YJ, Shen J, Chiu YL, et al. Indentation creep of an Fe-based bulk metallic glass. Intermetallics, 2009, 17: 190-194

33 Yoo BG, Oh JH, Kim YJ, et al. Nanoindentation analysis of timedependent deformation in as-cast and annealed $\mathrm{Cu}-\mathrm{Zr}$ bulk metallic glass. Intermetallics, 2010, 18: 1898-1901

34 Taub AI, Spaepen F. Ideal elastic, anelastic and viscoelastic deformation of a metallic glass. J Mater Sci, 1981, 16: 3087-3092

35 Castellero A, Moser B, Uhlenhaut DI, et al. Room-temperature creep and structural relaxation of $\mathrm{Mg}-\mathrm{Cu}-\mathrm{Y}$ metallic glasses. Acta Mater, 2008, 56: 3777-3785

36 Yang Y, Zeng JF, Volland A, et al. Fractal growth of the densepacking phase in annealed metallic glass imaged by high-resolution atomic force microscopy. Acta Mater, 2012, 60: 5260-5272

37 Tsai P, Kranjc K, Flores KM. Hierarchical heterogeneity and an elastic microstructure observed in a metallic glass alloy. Acta
Mater, 2017, 139: 11-20

38 Sarac B, Ivanov YP, Chuvilin A, et al. Origin of large plasticity and multiscale effects in iron-based metallic glasses. Nat Commun, 2018, 9: 1333

39 Ferry JD. Viscoelastic Properties of Polymers. 3rd ed. New York: Wiley, 1980

40 Argon AS. Plastic deformation in metallic glasses. Acta Metall, 1979, 27: 47-58

41 Ye JC, Lu J, Liu CT, et al. Atomistic free-volume zones and inelastic deformation of metallic glasses. Nat Mater, 2010, 9: 619-623

42 Ke HB, Zeng JF, Liu CT, et al. Structure heterogeneity in metallic glass: modeling and experiment. J Mater Sci Tech, 2014, 30: 560565

43 Li WH, Shin K, Lee CG, et al. The characterization of creep and time-dependent properties of bulk metallic glasses using nanoindentation. Mater Sci Eng-A, 2008, 478: 371-375

44 Gong P, Wang S, Li F, et al. Alloying effect on the room temperature creep characteristics of a Ti-Zr-Be bulk metallic glass. Physica B-Condensed Matter, 2018, 530: 7-14

45 Gong P, Jin J, Deng L, et al. Room temperature nanoindentation creep behavior of $\mathrm{TiZrHfBeCu}(\mathrm{Ni})$ high entropy bulk metallic glasses. Mater Sci Eng-A, 2017, 688: 174-179

46 Kissinger HE. Reaction kinetics in differential thermal analysis. Anal Chem, 1957, 29: 1702-1706

47 Ke HB, Xu HY, Huang HG, et al. Non-isothermal crystallization behavior of U-based amorphous alloy. J Alloys Compd, 2017, 691: 436-441

48 Zhao L, Jia H, Xie S, et al. A new method for evaluating structural stability of bulk metallic glasses. J Alloys Compd, 2010, 504: S219S221

49 Wang DP, Yang Y, Niu XR, et al. Resonance ultrasonic actuation and local structural rejuvenation in metallic glasses. Phys Rev B, 2017, 95: 235407

50 Böhmer R, Ngai KL, Angell CA, et al. Nonexponential relaxations in strong and fragile glass formers. J Chem Phys, 1993, 99: 42014209

51 Wang T, Yang YQ, Li JB, et al. Thermodynamics and structural relaxation in Ce-based bulk metallic glass-forming liquids. J Alloys Compd, 2011, 509: 4569-4573

52 Dyre JC. Colloquium: The glass transition and elastic models of glass-forming liquids. Rev Mod Phys, 2006, 78: 953-972

Acknowledgements This work was supported by the National Natural Science Foundation of China (51631003, 51871157 and 51601038), the Key Basic and Applied Research Program of Guangdong Province, China (2019B030302010), the Natural Science Foundation of Jiangsu Province, China (BK20171354), the Fundamental Research Funds for the Central Universities (2242020K40002), the Research and Practice Innovation Program for Postgraduates in Jiangsu Province (SJCX20_0038), and Jiangsu Key Laboratory for Advanced Metallic Materials (BM2007204).

Author contributions Yuan C, Lv Z, and Ma J planned the experimental work. Li X and Yang C carried out the sample preparation and ultrasonic-vibration experiments. Lv Z carried out the nanoindentation experiments. Pang $C$ carried out SEM and DSC measurements. Yuan C, Lv Z, Liu R, Pang C, and Ke H analyzed the experimental data. Yuan $\mathrm{C}$ wrote the paper with input and advice from $\mathrm{Ke} \mathrm{H}$, Wang W, and Shen B. 
Conflict of interest The authors declare that they have no conflict of interest.

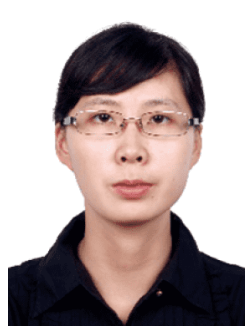

Chenchen Yuan received her MSc degree from Northeastern University, Shenyang, China, in 2009, and PhD degree from the Institute of Physics, Chinese Academy of Sciences in 2013. She is currently an associate professor at Southeast University, Nanjing, China. Her research interests focus on the electronic/atomic structure and its relationship with the mechanical properties of metallic glasses.

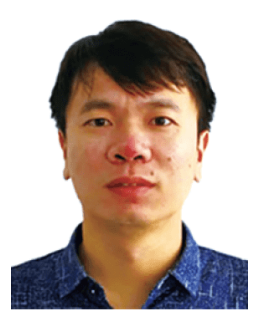

Haibo Ke received his $\mathrm{PhD}$ degree from the Institute of Physics, Chinese Academy of Sciences in 2012. He is currently a research professor in Songshan Lake Materials Laboratory, Dongguan, China. His research interests focus on the glass transition and structure relaxation behavior of metallic glasses.

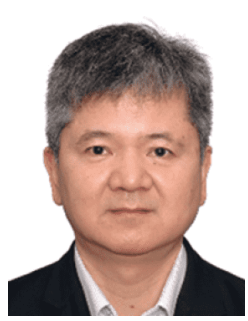

Baolong Shen received his MSc degree from Shanghai Research Institute of Materials, Shanghai, China, in 1991, and $\mathrm{PhD}$ degree from Himeji Institute of Technology, Japan, in 1999. $\mathrm{He}$ is currently a professor at Southeast University, Nanjing, China. His research interests focus on the structure and related properties (magnetism, mechanics, etc.) of ferromagnetic bulk amorphous alloys.

\section{锆基金属玻璃超声振动下的塑性流动行为}

袁晨晨 ${ }^{1 *}$, 吕祝薇, 庞昌蒙 ${ }^{1}$, 李信 ${ }^{2}$, 刘睿 ${ }^{1}$, 杨灿 ${ }^{2}$, 马将 ${ }^{2}$, 柯海波 ${ }^{3 *}$, 汪卫华 ${ }^{3,4}$, 沈宝龙 ${ }^{1^{*}}$

摘要 由于应力软化和表面快速扩散效应, 超声振动可以用于金属 玻璃微成型. 然而, 超声振动下的结构重排及其对金属玻璃力学响 应机制的影响仍不清楚. 本工作采用纳米压痕方法研究了超声振 动能量为 $140 \mathrm{~J}$ 的 $\mathrm{Zr}_{35} \mathrm{Ti}_{30} \mathrm{Cu}_{8.25} \mathrm{Be}_{26.75}$ 金属玻璃的塑性流动行为. 我 们采用Kelvin和Maxwell-Voigt模型分析了蠕变过程中的结构演化. 研究发现, 高频超声振动后样品的特征驰豫时间增长且驰豫峰增 强. 它有效地提高了玻璃转变和晶核生长过程中原子扩散的激活 能. 我们在超声振动样品中观察到较均匀的塑性变形行为, 还发现 超声振动之后加载速率对金属玻璃应力指数的敏感性减弱的现象. 本文有关共振驱动下的结构重排现象的研究有助于更好地理解非 晶态系统塑性流动行为的缺陷激活机制. 